\title{
La Remunicipalización del Agua en el marco de la Re-Definición de la Democracia. El Caso De Terrassa 1
}

\section{Edurne Bagué2}

Resumen: El presente texto se propone presentar la remunicipalización del agua urbana como mecanismo ante el neoliberalismo y sus conexiones con la búsqueda de formas para una mayor democracia. Para ello, el auge del común aparece como la herramienta que ha servido para repensar la remunicipalización como mecanismo para el impulso del cambio social.

${ }^{1}$ Este texto se basa en la tesis La remunicipalización del agua en Terrassa (Catalunya). La lucha de la Taula de l'Aigua por un modelo en torno al común (2013-2019).

2 edurne.bague@gmail.com. Universitat de Girona. Es doctora en Antropología Social por el Centro de Investigaciones y Estudios Superiores en Antropología Social (CIESAS) de México. Especializada en agua, sociedad y cultura ha desarrollado diversos estudios centrados en la relación entre democracia, ciudadanía e instituciones, así como la relación entre instituciones sociales y políticas gubernamentales. Sus ámbitos de estudio se centran en comunidades de regantes, nuevas gobernanzas del agua y análisis social de la remunicipalización. 
El caso más relevante entre los años 2015 y 2019 fue el de la ciudad de Terrassa, donde se remunicipalizó el servicio de agua urbana que hasta ese momento había estado controlado por Mina Pública d'Aigües de Terrassa S.A. Este proceso de remunicipalización culminó con la creación del Observatorio del Agua de Terrassa (OAT), que es una de les experiencias más innovadoras en gobierno de servicios con mecanismos de coproducción liderados por la propia ciudadanía organizada. Un espacio-herramienta que, toda vez que recoge el final de un camino, es puerta de entrada para la profundización de debates, así como para la apertura de líneas de trabajo que se extienden aumentando el alcance más allá del agua y de Terrassa.

Palabras clave: democracia, comunes, agua, vida, instituciones, remuncipalización

\begin{abstract}
This article intends to present the re-municipalisation of the management of urban water as a mechanism to oppose neoliberalism and highlight its connections with the search for new ways of achieving greater democracy. To do this, the rise of the notion of the 'common' seems to be the tool that has been used to re-think re-municipalisation as a mechanism to promote social change.
\end{abstract}

Between 2015 and 2019, the most relevant case of this was the city of Terrassa, where urban water supply-up to that moment in charge of the private company Mina Pública d'Aigües de Terrassa S.A.-was re-municipalised. This process of re-municipalisation gave rise to Terrassa's Observatory of Water, which is one of the

B CLIVATGE, número 8

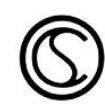


most innovative initiatives in public-supply management incorporating mechanisms of co-production led by the organized citizenry itself; a space-tool which, despite marking the end of the process, it is also the door to deeper debates as well as to the opening of new lines of work whose reach extends beyond water and the city of Terrassa.

Keywords: democracy, commons, water, life, institutions, remunicipalisation

Resum: El present text vol presentar la remunicipalització de l'aigua urbana com un mecanisme davant del neoliberalisme i fer paleses les seves connexions amb la cerca de formes d'assolir una major democràcia. Per això, l'auge del comú es presenta com l'eina que ha servit per repensar la remunicipalització en tant que mecanisme per a l'impuls del canvi social.

El cas més rellevant entre els anys 2015 i 2019 va ser el de la ciutat de Terrassa, on es va remunicipalitzar el servei d'aigua urbana que, fins a aquell moment, havia estat controlat per Mina Pública d'Aigües de Terrassa S.A. Aquest procés de remunicipalització va culminar amb la creació de l'Observatori de l'Aigua de Terrassa (OAT), que és una de les experiències més innovadores en govern de serveis amb mecanismes de coproducció liderats per la pròpia ciutadania organitzada. Un espai-eina que, a la vegada que que recull el final d'un camí, és porta d'entrada per a l'aprofundiment de debats, igual que per a l'obertura de línies de treball que s'estenen tot augmentant el seu abast més enllà de l'aigua i de Terrassa.

B CLIVATGE, número 8

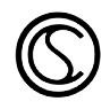


Palabras clave: democràcia, comuns, aigua, vida, institucions, remuncipalització

Resumen: El presente texto se propone presentar la remunicipalización del agua urbana como mecanismo ante el neoliberalismo y sus conexiones la búsqueda de formas para una mayor democracia. Para ello, el auge del común aparece como la herramienta que ha servido para repensar la remunicipalización como mecanismo para el impulso del cambio social.

El caso más relevante entre los años 2015 y 2019 fue el de la ciudad de Terrassa donde se remunicipalizó el servicio de agua urbana que hasta ese momento había estado controlado por Mina Pública d'Aigües de Terrassa S.A. Este proceso de remunicipalización culminó con la creación Observatorio del Agua de Terrassa (OAT), siendo una de les experiencias más innovadoras en gobierno de servicios con mecanismos de coproducción liderados por la propia ciudadanía organizada. Un espacio-herramienta que toda vez que recoge el final de un camino es puerta de entrada para la profundización de debates, así como la apertura de líneas de trabajo que se extienden aumentando el alcance más allá del agua y de Terrassa.

Palabras clave: democracia, comunes, agua, vida, instituciones, remuncipalización. 


\section{El contexto en el que surge la remunicipalización como fenómeno en Catalunya y el Estado Español}

La remunicipalización como fenómeno en el marco del Estado Español y Catalunya, se ubica en el contexto generado por la Crisis del 2008 y que tuvo lugar en un escenario más amplio de crítica a la globalización. Una crítica marcada por la necesidad de cambiar los modelos sociales y productivos (propuestas decrecentistas) que más tarde llevan al auge de la necesidad de la transición ecológica. De tal modo que son identificables las relaciones existentes entre la Crisis Multinivel y los cambios y tensiones sociopolíticos que cruzan la sociedad del Estado Español y Catalunya desde entonces, y que se han visto agraviadas con la Crisis del Covid-19.

En concreto, la importancia de la Crisis del 2008 estriba en que se abrió la lucha clara por la recuperación de los servicios públicos con el objetivo de frenar la externalización que caracteriza las políticas neoliberales implementadas en las décadas anteriores. Estas luchas se articulaban a través de las demandas de más democracia (Bagué, 2018).

Entre la Crisis del 2008 y el estallido del 15M, salió a la luz la Sentencia del Tribunal Constitucional (STC), contribuyendo a los debates en torno la democracia y la autonomía, comprendida como ejercicio de soberanía y derecho a decidir y el significado de la idea de democracia (Bagué 2020). La suma de estos factores penetraba así en una crisis que ya superaba la dimensión estrictamente económica, abarcando también, las dimensiones política y social. Esta coyuntura favoreció que aflorasen problemáticas más profundas, mostrando que lo que había era una crisis institucional

B CLIVATGE, número 8

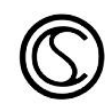


de largo aliento que cruzaba toda la sociedad 3 , de tal modo que la combinación de los factores supuso un parteaguas del que surgió un antes y un después ${ }^{4}$ (Bagué, 2020).

En este escenario el municipalismo se presentaba como un polo con potencial para la transformación social y democrática. Un espacio con potencial destittuyente e instituyente. Un espacio para el despliegue y desarrollo del común, dónde el alcance institucional de la Crisis Múltiple podía generar espacios para (re)pensar el municipio como institución social (Calle y Vilaregut, 2015; Observatorio Metropolitano, 2015).

El fenómeno de la remunicipalizacón es muy extenso y asciende ya a 1408 en 58 países (TNI, 2020). El servicio que más se asocia a la remunicipalización es el del agua urbana, aunque no se limita a él y favorece la inclusión de cambios en el gobierno de estos servicios (Lobina, 2019; Bagué, 2020). En el Estado Español y Catalunya esto es observable a partir del 2011 tanto en la lucha como en el perfil de los actores involucrados en este proceso (Bagué, 2018) coincidiendo con las respuestas sociales derivadas de la situación

\footnotetext{
${ }^{3}$ En palabras de Radic (2016) "en este sentido, entendemos la coyuntura actual como la manifestación de un proceso más profundo y complejo -estructuralque devela los cambios a los que asiste España en la globalización"

${ }^{4}$ Si bien es rastreable un continuum de movilizaciones desde los gobiernos de José María Aznar, presidente del Gobierno de España durante los años 19962004, con las movilizaciones del No a la Guerra, contra la guerra de Iraq o Antiglobalización. En el caso de Catalunya desde 2008 se inició un ciclo de movilizaciones importante que empieza con las luchas de estudiantes contra la reforma del Espacio Europeo de Educación Superior (EEES) o Plan Boloña y que siguió con huelgas generales.
}

B CLIVATGE, número 8

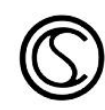


después de la Crisis de 2008 como la falta de empleo, dificultades de acceso y mantenimiento de la vivienda de forma generalizada y la privatización de la sanidad ${ }^{5}$. Unas respuestas sociales con repercusiones a lo ancho y largo de los territorios del Estado Español y que se identificaban con el 15-M y que ponían de manifiesto la desconexión entre el modelo económico y político y las necesidades básicas de la sociedad. El acceso al agua era parte de estas respuestas (Bagué, 2020).

Así, la remunicipalización aparece como un espacio que contribuye a repensar las instituciones y las relaciones entre ciudadanía y estructuras y formas de gobierno. Estos elementos cruzan el trabajo que desde 2014 lleva a cabo la Taula de l'Aigua de Terrassa por medio de la remunicipalización del agua de esa ciudad. Una propuesta que se proponía también, democratizar las instituciones municipales y que ha servido de inspiración para el impulso de procesos de remunicipalización en otras poblaciones. Una línea de trabajo que se vio fortalecida por la presencia en la arena representativa, durante el período 2015-2019, de formaciones políticas asociadas a la emergencia post Crisis y Post $15 \mathrm{M}$, en el marco del asalto institucional. Se trataba de la búsqueda de respuestas de una sociedad que tiene serios choques con el sistema y el articulado actual en una realidad que, de forma constante,

\footnotetext{
${ }^{5}$ En concreto los primeros años de la remunicipalización del agua urbana en Catalunya se centraron en la generación de los discursos que señalaban al Grupo AGBAR como un actor privado con intereses lucrativos y mercantiles sobre el agua y la constitución de la Plataforma Aigua és Vida $(\mathrm{AeV})^{5}$ (Bagué, 2020).
} 
comprueba los límites epistemológicos del sistema, pero que aún no tiene referentes para resolver o superar la situación actual. En este sentido, es importante comprender las instituciones como el espacio en que los campos epistemológicos toman forma $\mathrm{y}$ organizan la vida, para poder dialogar y extraer de la experiencia que se analiza de la remunicipalización del agua urbana en la ciudad de Terrassa, hasta dónde podemos comprender que abre puertas a cambios más profundos, y hasta dónde, no es más que una experiencia más dentro de los marcos ya instituidos de acción y gobierno.

\section{El común como propuesta}

La Crisis de 2008 puso en evidencia el nivel de corrosión y

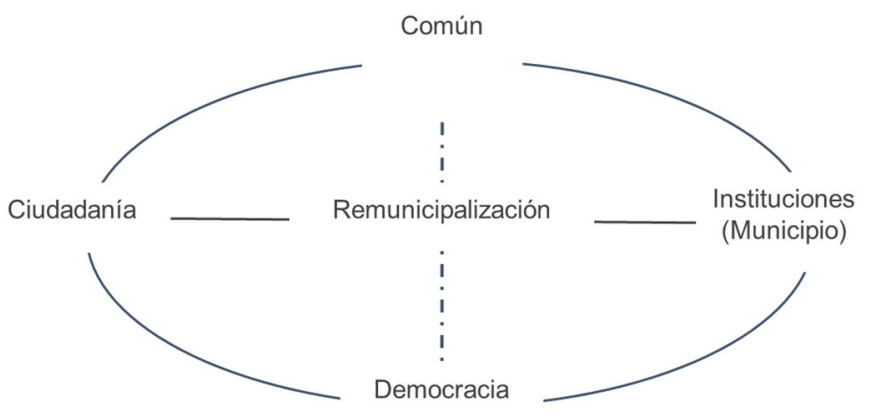

Ilustración 1 Relación de los elementos que intervienen en la remunicipalización del agua. Elaboración Propia.

debilidad de unas instituciones que, ante la tensión latente y duradera del mercado (Macpherson, 1977), acabaron sucumbiendo a él, debilitando a la democracia (Brown, 2010; Agamben, 2010; Rendueles y Subirats, 2016; Laval y Dardot, 2015; 
Harvey, 2013; Garcés, 2013). La Crisis económica mostró la profundidad de la problemática cuando puso en evidencia que las personas habían ido cediendo la toma de decisiones y el ejercicio de gobierno. El desencanto institucional y la profunda crisis social, política, ecológica y económica, o sea, civilizatoria (Pérez, 2014, Herrero, 2011; Herrero, 2015) ${ }^{6}$ o paradigmática actual explican la crisis del estado y de la democracia, así como la propia emergencia del común (Laval y Dardot, 2015; Harvey, 2013; Hardt y Negri, 2011; Herrero, 2015; Jiménez y Puello-Socarrás 2017; Pérez Orozco, 2014; Rendueles y Subirats, 2016; Garcés, 2013). Con la Crisis del 2008 se pusieron en entredicho algunos elementos fundamentales hecho que abrió la puerta a la aparición de cambios en el imaginario colectivo en torno la concepción que se tiene del mundo, sus valores y los principios que lo deben articular.

Las debilidades de la democracia liberal se concretaron en el hecho de que a medida que la política neoliberal ha ido reduciendo el financiamiento de los bienes públicos, se ha ido reduciendo el bien común disponible (Harvey, 2013; Brown, 2010), obligando a los grupos sociales a buscar otras vías para mantener estos bienes (Harvey, 2013; Jiménez y Puello-Socarrás, 2017; Puello-Socarrás, 2016; Federici, 2010; Laval y Dardot, 2015). Hasta el punto en que la crisis económica y política condujo a la necesidad del cambio político, sus condiciones sociales, los compromisos y las normas

6 En palabras de Amaia Pérez Orozco se trata de "una crisis civilizatoria, del conjunto del proyecto modernizador; aunque esto no signifique que el mundo vaya a cambiar mañana, hablamos de un proceso histórico que excede probablemente el lapso de nuestras vidas concretas (Pérez, 2014:223).

B CLIVATGE, número 8

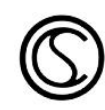


que constituyen una comunidad política (Rendueles y Subirats, 2016) ${ }^{7}$. Es decir, cuando el Estado abandona sus supuestas obligaciones en tanto que institución proveedora, la ciudadanía toma la iniciativa de recuperar esta función común y colectiva de acceso a estos bienes (Harvey, 2013). En la acción de organizarse para poderse proveer, emerge como entidad política, como sujeto con capacidad de incidencia. Es lo que Garcés señala como el nuevo nosotros, un nuevo sujeto y otra concepción de la ciudadanía en un marco de mundo en común (Garcés, 2013).

Por lo tanto, el sentido común ante la situación de desposesión acelerada de todos los espacios vitales es lo que conlleva la emergencia de una nueva forma de oponerse al capitalismo, incluso a su superación (Laval y Dardot, 2015; Jiménez y Puello-Socarrás, 2017). De tal modo que ya no se trata del futuro de la democracia

${ }^{7}$ El aumento de la base electoral durante el siglo XX ha repercutido en un rompimiento de la noción de ser representantes de una comunidad respecto la cual hay una responsabilidad por defender unos intereses, para pasar a ser electos de una masa indefinida de personas variadas, con las que no se tiene vínculo alguno (Macpherson, 1977). La responsabilidad se ha diluido hasta el punto de no ser necesario el cumplimiento ni la asunción de dicha responsabilidad. Esta falta de sentido de responsabilidad y conexión entre aquello que se encarga a los representantes y aquello que los representantes asumen como responsabilidad (Subirats, 2005; Rendueles y Subirats, 2016), lo que ha resultado ser uno de los argumentos detonantes para el cuestionamiento del sistema en su conjunto.

B CLIVATGE, número 8

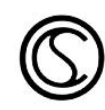


liberal, si no del futuro de la democracia. ¿Qué es en pleno siglo XXI la democracia?

Así pues, sobre la mesa está el reformular la idea misma de democracia, de acuerdo con los valores, los principios y la situación actual, que incluye la necesidad de incluir de forma axiomática dos ejes fundamentales. Por un lado, las formas de gobierno participado y colectivo arraigado al espacio, fundamentado en los vínculos y las relaciones (Zibechi en Jiménez y Puello-Socarrás, 2017). Y, por el otro, la asunción de la realidad ambiental - de un cambio climático irreversible y la finitud del acceso a los recursos -, lo que conlleva a una comprensión de la sustentabilidad comprendida en clave de durabilidad en el tiempo. Esto implica la asunción de formas de gobierno más participadas y colectivas. Ambos aspectos son cruciales y colisionan de forma frontal con el espíritu del liberalismo (y de la modernidad) basado en el crecimiento y la expansión continuada y de forma infinita como forma de estar y relacionarse con el mundo (Bagué, 2020).

A partir de aquí, pensar en democracia, desde un contexto que cruza las sociedades y lugares recónditos del planeta en el siglo XXI, $\mathrm{y}$ con las experiencias y conocimientos acumulados, implica comprender que parte de la superación del capitalismo y su paradigma social, pasa por asumir que es importante recuperar el gobierno como una práctica vinculada a la generación de comunidad y toma de decisiones colectiva. Por lo tanto, democracia, entrados en el siglo XXI, se asocia con el ejercicio del gobierno desde lógicas y prácticas participadas basadas en la negociación y la interdependencia colectiva y no con la realización de la libertad individual absoluta (Bagué, 2020).

B CLIVATGE, número 8

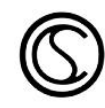


Es así como el común aparece como una salida ante dicha situación en un intento por redefinir y avanzar hacia una propuesta de cambio socio-institucional más democrática, más participada por las personas 8 (Laval y Dardot, 2015; Bagué, 2020). Es en la búsqueda de respuestas, que la promesa de lo común adquiere sentido y emerge para hacer frente a los problemas sociales que se afrontan, más aún cuando las herramientas y mecanismos existentes ya no son útiles (Rendueles y Subirats, 2016). Se trata de la recuperación de la soberanía, entendida como capacidad de decidir, como ejercicio de democracia y autogobierno y se asocia a democracia, cercanía, igualdad y justicia.

Para Laval y Dardot (2015), el quid de la cuestión reside en transformar profundamente la economía y la sociedad "invirtiendo el sistema de las normas que amenaza ahora de forma directa la humanidad y la naturaleza" (Laval y Dardot, 2015:17). Y alertan de que seguir esperando que el estado-nación sea quien proteja de forma eficaz a la población de la situación de acaparamiento por parte de los mercados, de la deslocalización y del cambio climático,

${ }^{8}$ Con el escenario posterior a la crisis y las nuevas preguntas que se estaban empezando a dar en el seno de la sociedad del conjunto del Estado Español, los comunes empezaron a erigirse como mecanismo y herramienta de lucha para promover un cambio en el modelo de sociedad. Hasta el momento, el conocimiento sobre su existencia no estaba presente de forma amplia en el conjunto de la sociedad - a pesar de existir en muchos lugares - y el conocimiento que existía se centraba en su realidad como experiencias históricas que aún existían de formas de organización social y normatividad, sobre todo propias de zonas rurales (Chamoux y Contreras, 1996; Montesinos, 2011; Beltran y Vaccaro, 2017; Roigé et alt, 1993; Congost, 2007)

B CLIVATGE, número 8

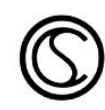


"es ilusorio" (Laval y Dardot, 2015) puesto que, dentro del sistema actual, son estos los que ocupan un lugar clave para aplicar las necesidades del capitalismo actual, financiero y deslocalizado, que no conoce de límites en la práctica de la mercantilización y la acumulación. Para los autores, se trata de someter las instituciones a la actividad social y a la participación política de la mayoría. El estado se ha sustentado sobre prácticas de espolio público desamortizaciones, titularidad pública que ha enajenado a la sociedad sobre las decisiones de aspectos públicos (comunes), donde el gobierno y las decisiones, se toman al margen de la sociedad - que han acabado siendo gestionados desde lógicas de gestión privada.

Afirmación que apuntala la importancia del municipalismo como recuperación del autogobierno, como la institución de provisión y garantía de estos derechos, desde la proximidad. Un autogobierno que se caracteriza por ejercerse de forma más participada, comprendido como el ejercicio del gobierno desde instituciones propias y no ajenas, que interceden con el propósito de hacer cumplir mandatos originados al margen del espacio local (Bagué, 2020). Un municipio que se contrapone a una estructura estatal que tiene una dimensión muy delegativa de hacer en nombre de otros y esto desmotiva la implicación de la gente en sus propios problemas colectivos (Rendueles y Subirats, 2016).

Por esto, el municipalismo derivado del 15-M buscaba articular respuestas creativas y arraigadas en valores y abrió un nuevo ciclo como espacio de reconstrucción democrática de la política y de construcción del bien común (Gomà y Blanco, 2016). Se trataría, por lo tanto, y siguiendo a los autores, de un municipalismo de

B CLIVATGE, número 8

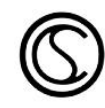


cambio y de acuerdo con los mandatos ciudadanos de transformación y entendimiento (Gomà y Blanco, 2016; Calle y Vilaregut, 2015). Por lo tanto, recaía sobre las autoridades municipales, tanto políticas como de la administración, el deber de procesar lo que Gomà y Blanco (2016) llaman "doble vía de innovación" que incluía las políticas públicas y las formas de gobierno (gestión y participación). Se empieza así a incorporar la noción de común en el municipio ${ }^{9}$ de tal modo que se cambia el lugar de referencia desde el que la sociedad construye institución para la recuperación del control. De este modo, la acción de comunalizar está directamente relacionada con un cambio del

9 El gobierno local en Catalunya tiene su origen, en la necesidad de tomar decisiones sobre la tierra, sobre los recursos para dar viabilidad a la subsistencia de los grupos. Este hecho, institucionalmente, se formalizó en el contexto urbano en Catalunya con las universidades, nombre que reciben los primeros gobiernos urbanos locales. Así pues, se puede establecer que las instituciones de gobierno local históricamente han estado han estado estrechamente vinculadas al territorio, así como también, en el hecho de que el municipio devenga el espacio institucional de referencia para la re-localización de la gestión. Una concepción que va de la mano de la propuesta de territorio a partir de la teoría del actor-red de Latour (2005) o del territorio como lugar de vida dinámico que plantea Escobar "una fabricación de un mundo sociocultural" que está relacionado con la complejidad de las relaciones entre los dominios biofísicos y humanos, "que dan cuenta de las configuraciones particulares de la naturaleza, (...) paisaje y lugar como entidades vivenciadas y profundamente históricas" (Escobar, 2010: 46). 
papel del Estado como institución de provisión de estos bienes comunes Harvey (2013). Es en este sentido que el común emerge para fortalecer las instituciones mediante su re-organización y reconceptualización, es decir, la comunalización de las instituciones públicas.

En este contexto, la remunicipalización aparece como una práctica para la recuperación del control sobre la vida. Una vida que se comprende en un espacio cercano y concreto, hecho que contribuye a dar centralidad al espacio local interpelando directamente a la dimensión sociopolítica del municipio como espacio que se imbrica también con la concepción de comunidad y que se expresa en la participación y el ejercicio de la democracia. De este modo, el espacio municipal aparece como aquel en el que es posible romper con la distancia y el aislamiento que caracteriza las instituciones. De este modo, la remunicipalización se articula sobre la noción de común en tanto que permite la restauración de un espacio de vínculos, relaciones y elementos que conforman lo colectivo (Harvey, 2013). Un vínculo que envuelve lo político y lo social, es decir, entre la ciudadanía y las instituciones, pero también entre la propia ciudadanía.

Ahora bien, la remunicipalización del agua tiene que ver con servicios públicos motivo por el cual, remunicipalizar desde el común abre la puerta a las relaciones entre lo público y lo común. Siguiendo con este planteamiento, cuando se introduce la posibilidad de comunalizar, la acción alude a la recuperación de una 
parte de una institución que también fue expoliada ${ }^{10}$. En este sentido, no se trata de un bien en términos materiales, se trata de un espacio articulador de la sociedad. Por lo tanto, se diría que se busca comunalizar parte del espacio institucional que fue previamente enajenado. Pero no se trata sólo de un servicio púbico, sino del carácter vital del agua $\mathrm{y}$, por lo tanto, inalienable de la propia vida hecho que incide en que no puede estar al margen de los espacios institucionales de gobierno.

En remunicipalización del agua, escoger vías de comunalización al margen de los espacios de gobierno municipal, por lo tanto, de las instituciones de lo público, supone debilitar una institución de raíz y trayectoria de autogobierno, y facilitar la pauperización de las condiciones de las personas. En materia de agua, comunalizar sin entrar en el campo de lo público, supone incurrir en el avance de una comunalización en clave de neoliberalización, es decir, debilitando y atomizando. Al tratarse de un servicio público básico

10 Los comunes han sido el sujeto de las luchas que ayudan a comprender que el desarrollo del capitalismo como un proceso continuado basado de forma fuerte en procesos de desposesión por medio de los cuales se expulsa a las personas de la tierra o de sus significados de subsistencia para facilitar su absorción en el sistema productivo industrial (Opazo, 2015). el común siempre ha estado en una relación de tensión con el Estado en su expansión como materialización, sobre todo desde el siglo XIX, de sistema social liberal, del marco económico del capitalismo, el mercado desde la alienación entre la producción y el producto, por vía del trabajo asalariado y como modelo de concentración de los recursos (acaparamiento) y de la toma de decisiones. (Laval y Dardot, 2015; Montesinos, 2013; Opazo, 2015).

B CLIVATGE, número 8

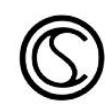


y esencial, de arraigo histórico local, que cuenta en su haber con fórmulas de manejo y gobierno colectivo, aunado al hecho de que se trata de un elemento que es inalienable de la vida misma, hacen que el objetivo de la comunalización del servicio sea la recuperación del municipio como estamento que también fue cercado, avanzando de forma cualitativa y profunda en la experimentación de las prácticas instituyentes del común.

\section{La remunicipalización ante el avance del neoliberalismo}

La remunicipalización no puede entenderse sin tener en cuenta los escenarios que la promovieron. Las primeras luchas por la remunicipalización tuvieron lugar principalmente en países de América Latina en los primeros años de la década del 2000.

En Bolivia, el conflicto por la entrada de las Aguas del Tunari abrió la puerta a cambios de gran calado que marcaron el rumbo de la historia del país. Es así como con la Guerra del Agua de Cochabamba se inició la remunicipalización como recuperación de la gestión por parte de las instituciones públicas, frente a las grandes empresas multinacionales (Ceceña, 2004; Grosse et al., 2006; Hall, 2005). En esos mismos años, tuvo lugar la remunicipalización de la gestión del agua en Uruguay y localidades de Argentina, en ambos casos se trató de reestatalizaciones (Grosse et al., 2006) en contextos de emergencia política, como la crisis argentina. El caso de Uruguay fue uno de los ejemplos más notorios de cómo a través de un referéndum, la sociedad uruguaya frenó la privatización del agua. Finalmente, otro caso destacable fue el de Venezuela donde a

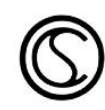


principios de los 2000 tuvo lugar la Revolución Bolivariana de la mano de Hugo Chávez (Bagué, 2020).

Estas luchas fueron la respuesta a la desposesión y el expolio de la economía neoextractivista sobre los recursos naturales y las privatizaciones de los servicios urbanos de abastecimiento. Se trataba de la aplicación de políticas de ajuste estructural que venían promocionadas por órganos como el Banco Mundial, el Banco Iberoamericano de Desarrollo o el Fondo Monetario internacional que introducían medidas de desmantelamiento del Estado en los diferentes países (McDonald, 2013) ${ }^{11}$. Por su parte Lobina comentaba que las experiencias directas con los problemas habituales de la gestión privada del agua —-desde falta de inversión en infraestructuras hasta subidas tarifarias $y$ riesgos medioambientales- han convencido a comunidades $y$ responsables de políticas que el sector público está mejor preparado para prestar servicios de calidad a la ciudadanía y para fomentar el derecho humano al agua (Lobina et al., 2015).

Por lo tanto, la remunicipalización surgió de estos contextos de cambios y resistencias a la privatización y fueron los países del llamado Sur Global los que aportaron reivindicaciones más estructurales poniendo en marcha auténticos laboratorios que

${ }^{11}$ McDonald apuntaba que "el Banco Mundial y muchas agencias de Naciones Unidas todavía abogan por la participación del sector privado en los servicios de agua y continúan invirtiendo en think tanks, conferencias y publicaciones que promueven y financian la intervención privada en los servicios de agua en todo el mundo" (McDonald, 2013: 8), y prosigue "No es sorprendente que, al mismo tiempo, continúe la resistencia a estas tendencias comercializadoras" (McDonald, 2013: 9).

B CLIVATGE, número 8

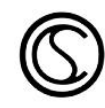


buscaban poner en práctica los preceptos defendidos en las luchas de recuperación de la gestión en el ámbito de la gestión pública del servicio de abastecimiento (Bagué, 2017).

A partir de aquí, podemos entender cuál es el sentido y de dónde viene el interés en poner el acento en los puntos que caracterizan la remunicipalización como el control social ciudadano, la escala local y la sostenibilidad ecológica entendidos éstos, como otras formas de relación con el territorio que buscan la democratización de la gestión y la desmercantilización del agua, que pasa por que ésta sea entendida como un bien común y no como un recurso (Bagué, 2016), incluyendo una gestión pública completa que permita la posibilidad de incluir formas de gestión colectiva (Kishimoto et al., 2015).

Por ello, la remunicipalización del agua tiene un fuerte componente transformador (Lobina, 2019; Bagué, 2020) que se puede ver en el hecho que comportó el cuestionamiento estructural de las medidas que se habían estado aplicando a nivel internacional en las últimas décadas, abriendo la puerta a las posibilidades de hacer frente al desmantelamiento de los Estados desde ámbitos de trabajo concretos (Bagué, 2017), que se traducían en formas de gobierno y sus aspiraciones de transformar la sociedad. Se trata de un proyecto económico, político y social emancipador que puede subvertir el urbanismo neoliberal al invertir las prioridades de la provisión de servicios de la búsqueda del beneficio privado a la de la prosperidad colectiva (Hall et al., 2013; Becker et al., 2015; McDonald, 2016; Lobina, 2017; Cumbers y Becker, 2018 en Lobina, 2019: 726).

B CLIVATGE, número 8

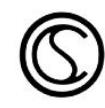




\subsection{La comunalización del agua urbana como fuente de derechos para la sostenibilidad de la vida}

La Crisis también sirvió para poner en evidencia que el agua con el transcurso de los siglos, y de forma explícita y clara en las últimas décadas, había pasado por un triple proceso de cercamiento, desposesión y enajenación que culminaba con una lógica naturalizada de su alienación y posterior mercantilización que han sido la base para que se dieran escenarios de vulneración de derechos y afectaciones ambientales, sobre todo, desde que en el año 2010 la asamblea de las Naciones Unidas considerara el acceso al agua como un derecho humano ${ }^{12}$. Esta premisa se hace patente

12 “En noviembre de 2002, el Comité de Derechos Económicos, Sociales y Culturales de las Naciones Unidas adoptó su Observación General no 15 sobre el derecho al agua, estableciendo que "El derecho humano al agua es el derecho de todos a disponer de agua suficiente, salubre, aceptable, accesible y asequible para el uso personal y doméstico". El acceso universal al saneamiento "no solo reviste una importancia fundamental para la dignidad humana y la vida privada, sino que constituye uno de los principales mecanismos para proteger la calidad" de los recursos hídricos. Además, en abril de 2011, el Consejo de Derechos Humanos reconoce, mediante su Resolución 16/2, el acceso seguro al agua potable y al saneamiento como un derecho humano: un derecho a la vida y a la dignidad humana" 12 . Sin embargo, a pesar de la declaración de Derecho Humano, actualmente pervive una situación elevada de hogares que continúan sin tener acceso al agua en cantidad y calidad suficiente para poder llevar a cabo una vida en condiciones óptimas de salubridad. A esta situación, se suma otra realidad que con los años de concienciación tampoco parece haber disminuido, como los desplazamientos de poblaciones y comunidades, por la construcción de grandes infraestructuras hidráulicas o energéticas, que muy a menudo van de la mano. Ambos casos cuentan con estudios sobre impacto, situación y

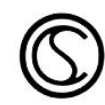


cuando la relación entre la ciudadanía y el servicio está establecida en términos de empresa/cliente. De ahí que las empresas hayan podido estar ejerciendo presión practicando cortes de suministro por falta de pago en una transformación del espacio de la política pública al ámbito mercantil. Frente a esta situación han tenido lugar procesos de respuesta que buscan protegerla y extraerla de esa realidad (Lobina et al., 2015; Kishimoto y Petitjean, 2017; McDonald, 2013; McDonald, 2018; Hall, 2005; Grosse, et al., 2006). Estas lógicas extractivas y enajenadas del agua son el reflejo y la concreción de marcos de comprensión (ontológica y epistemológica) que tienden a reducir el agua a un hecho biológico cuando se piensa que "es naturaleza", pero el agua es social y toma formas concretas que están conectadas con el dominio de la salud pública y las nociones populares (Caton y Orlove, 2010). En este sentido, Harstrup apunta que es necesario hacer un acercamiento antropológico como vertiente para un futuro sustentable porque el agua no es una abstracción, tiene valor económico y moral, pero también agencia porque influye en la sociedad porque tiene fuerza transformadora (Harstrup, 2013) y es desde el proceso de enajenación que surge la anulación de la conciencia de la interdependencia.

Extraer el servicio de agua urbana de la lógica mercantil y empresarial para garantizar la sostenibilidad de la vida digna

contexto, y específicamente, en lo que al acceso doméstico se refiere, de forma reiterada, puesto que es un objetivo muy presente en las políticas de agua impulsadas por organismos como el Banco Mundial (BM) o el Banco Interamericano de Desarrollo (BID).

B CLIVATGE, número 8

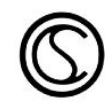


humana y no humana, se relaciona con la recuperación del control sobre su manejo y gobierno. Es en este contexto donde tiene lugar la recuperación del servicio desde el común. Hecho que se traduce en debates acerca de los cambios en su estructura y concepción en tanto que básico, para poder desmercantilizar el agua por su carácter inalienable. Ello es indicativo de que se está en vías de producir una reformulación del agua como común en el contexto actual urbano del siglo XXI. Es por esto por lo que garantizar la sostenibilidad de la vida pasa por recuperarla y extraerla de la esfera del mercado y la lógica mercantil y después por desarrollar un acceso que garantice esa sostenibilidad de la vida, tanto humana como no humana. Ello implica tener que recuperar su control por parte de la comunidad/comunidades. Es decir, llevar a cabo una acción de comunalizar, para poder acceder a su control, en formas de manejo y gobierno, situados en el marco no mercantil relacionado con el territorio y que garantice la vida digna y el acceso a las personas de forma universal. Esta noción de común no se da en los términos históricos y clásicos de la gestión comunal, si no en una traducción epistemológica y ontológica del mundo.

El agua es común más allá de su cualidad de bien y recurso, porque la comunidad, las personas que la defienden, consideran que es inalienable e inapropiable de la propia vida, porque es el pilar de la vida misma ${ }^{13}$. Y no es una decisión asociada a la propiedad sobre

${ }^{13}$ Langford y Khalfan (2006) detectaron que como efecto de la mercantilización del agua surgen respuestas por parte de la sociedad afectada, que defienden que el agua contiene valores sociales en ella misma por los cuales no puede

B CLIVATGE, número 8

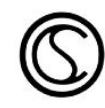


ella, sino al papel que tiene para la sostenibilidad de vida misma para la comunidad -que le otorga el estado de común. Por lo tanto, se desplaza de una concepción de recurso de uso compartido, centrado en su gestión por parte de las personas que tienen acceso a ella, la mayor parte de las veces, a través de la tenencia de la tierra, para ser un común generado por la propia comunidad a partir del acto de comunalización (Harvey, 2013). Es decir, el acto a partir del cual se establece una relación con ella con la doble finalidad de aislarla de la dimensión del capital (la mercantilización) y democratizar las decisiones que se tomen relativas a ella y sus usos para garantizar derechos como el Derecho Humano al agua (Bagué, 2020).

establecerse como un elemento de mercado que se regule según estas leyes. Estos grupos frente al agua mercancía ponen el agua como vida que debe ser extraída de su lógica mercantil y así recuperar la gestión del agua es recuperar el control sobre la vida e instan a la administración pública a comprometerse en dar respuesta a este tipo de situaciones. El Derecho Humano al agua, así como las distintas iniciativas que se están promoviendo en este sentido, son una puerta a un debate complejo lleno de contrariedades y de base profundamente epistemológica. En la actualidad se han habilitado distintas iniciativas para hacer frente a los cortes de suministro y así cumplir con el Derecho Humano al agua y garantizar el mínimo vital. La mayoría de las propuestas se centran en bolsas de ayuda que se ponen al servicio de los servicios sociales municipales que sirven para pagar las facturas que quedan impagadas por parte de abonados que no están en disposición de hacerlo. Estas soluciones tienen un carácter paliativo, pero no estructural y con ellas, las empresas siguen sin percibir las repercusiones de sus políticas tarifarias.

B CLIVATGE, número 8

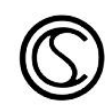


En estos términos, remunicipalizar, en tanto que supone la asunción del control y responde a la inquietud de querer recuperar y extraer el agua de las lógicas del mercado, es un acto de comunalización.

\subsection{El servicio de abastecimiento de agua en Catalunya}

El patrón que se observa en Catalunya a partir de la situación actual del servicio muestra que alrededor del $80 \%$ de la población vive en ciudades con gestión indirecta (Planas, 2017)14. Y que la gestión directa se lleva a cabo en las poblaciones pequeñas. La suma de estas dos informaciones pone de relieve que se reserva la gestión indirecta a los espacios que permiten beneficio industrial, las ciudades, mientras que se reserva la gestión directa a las poblaciones pequeñas en las que no es posible el margen de beneficio económico (Badia y Subirana, 2015).

Tabla 1 Situación de la gestión del agua en Catalunya

\begin{tabular}{ll} 
Municipio & Población \\
\hline Pública: 506 & 1.235.606 habitantes \\
\hline Privada: 394 & $\begin{array}{l}\mathbf{6 . 3 1 7 . 5 8 3} \\
\text { habitantes (mixta- } \\
\text { privada) }\end{array}$ \\
\hline
\end{tabular}

Población total Catalunya:

7.553.189 habitantes

Fuente Aigua és Vida, 2015

14 De estas poblaciones el $70 \%$ de los casos se trata de concesiones con filiales de AGBAR, que pertenece al Grupo SUEZ (Planas, 2017). 
De hecho, el escenario catalán es una realidad oligopólica, principalmente de grupos filiales de AGBAR con cerca de un $70 \%$ de servicios, aunque a nivel mundial son tres los grupos empresariales transnacionales (Veolia, Suez, Bechtel). Este hecho acentúa más aún la vulnerabilidad en la que se encuentran administración y ciudadanía ante una gestión opaca de este servicio. Los titulares del servicio son las administraciones públicas, pero en régimen de concesión, no tienen acceso a los datos que genera el servicio de tal modo que pierden su capacidad de control.

Esta situación en parte se relaciona con la naturaleza y el origen del servicio, dado que sus necesidades tecnológicas y económicas favorecen la economía de escala y por lo tanto la concentración de capacidades que luego se convierten en poder y recursos ante los cuales las administraciones públicas locales se encuentran desprovistas para hacer frente. A ello se le une el hecho de que el servicio se encuentra concesionado en muchos casos con contratos con diversidad jurídica, desde contratos antiguos como los de Barcelona o Terrassa, hasta algunos recientes. Todo ello contribuye a una monopolización del conocimiento asociado al servicio (know how) y otros servicios derivados, así como el acaparamiento del espacio de innovación e investigación de las universidades (Bagué, 2020). Esto explica por qué se trabaja desde una visión lucrativa del servicio donde el agua es una mercancía que se compra, consume y paga. Esta concepción acaba conllevando actitudes extractivas con el agua. Si bien se avanza mucho en tecnología y

B CLIVATGE, número 8

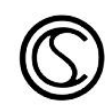


sustentabilidad, es una tecnología pensada para poder mantener el ritmo de producción económica. Por lo general, el marco que ha estado rigiendo en el sector hasta los últimos años ha estado que los ciudadanos son clientes y es desde esa realidad que las empresas operadoras se relacionan con ellos. También cabe destacar que, al tratarse de empresas de capital privado en régimen de concesión, rige el derecho mercantil, hecho que tiene afectaciones en la obligatoriedad de la transparencia y la rendición de cuentas (Bagué, 2020).

Para comprender estos rasgos que caracterizan el servicio es importante acercarse a su origen y sus antecedentes de los que procede.

\subsection{Mirada histórica de la gestión del servicio de abastecimiento de agua de las ciudades}

El servicio básico de abastecimiento aparece en la segunda mitad del siglo del siglo XVIII en ciudades como Londres o París, y se extiende de forma generalizada a principios del siglo XIX, coincidiendo con el impulso tecnológico de la Revolución Industrial (Heredia, 2014) y la extrapolación de la ingeniería a la mejora de los servicios urbanos. Su aparición supuso un cambio en la lógica de la accesibilidad ${ }^{15}, \mathrm{y}$, por lo tanto, también de los mecanismos que

15 En estos términos, Castro (2005) destaca que en el Reino Unido aparecieron los "ladrones del agua" coincidiendo con el momento de implementación de este sistema domiciliario y que nos indica que conllevó un cambio estructural en la relación con el agua.

B CLIVATGE, número 8

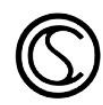


permiten ese acceso. Hasta ese momento el abastecimiento público se comprendía como la distribución gratuita mediante acueductos y fuentes públicas, en sistemas que también contemplaban fuentes privadas (Heredia, 2014; Pastallé y Solé, 2002; Simón y Matés, 2010). Este cambio se explica por las aportaciones de Linton quien establece la idea de que el ciclo hidrológico es un hecho establecido, dando paso a una noción del agua como recurso abstracto que puede ser medido y contado hecho que contribuye en el cambio y la transformación de las formas de relación y concepción del agua hasta el día de hoy, y que quedan reflejados en las formas de gestión (Harstrup, 2013).

Se pueden agrupar en tres los elementos que en términos generales explican la naturaleza de este servicio. En primer lugar, la innovación tecnológica como uno de los motores principales del sector (Matés 2009). En segundo lugar, la industrialización con los cambios en los medios de producción y los cambios en el modo de asentamiento, formas de vida y desplazamientos a núcleos urbanos donde poder acceder al trabajo asalariado. Esto se tradujo en cambios en el consumo, un proceso de consolidación de nuevas élites económicas - la nueva burguesía industrial y financiera - con un auge de la producción que se vinculaba con el progreso. En este contexto, la llegada del sistema de abastecimiento, de manos de la iniciativa privada, se convierte en un producto de la economía de mercado, que necesita de grandes inversiones para alcanzar el reporte de beneficios (Heredia, 2014). Por ello el sistema de abastecimiento se vuelve un elemento representativo de ese

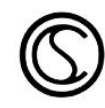


momento histórico con el que llega la nueva concepción del agua como bien privado. Y finalmente, el movimiento higienista en el siglo XIX, en Europa y Estados Unidos (Castro, 2005, Matés, 2016). Este movimiento impulsó la necesidad de garantizar el acceso al agua de calidad apta para el consumo humano con la finalidad de evitar epidemias. Estas garantías quedaron plasmadas en la regulación para el control de la calidad y la infraestructura16. De hecho, las iniciativas privadas no tenían capacidad de ampliar la cobertura a los barrios de rentas más bajas (Bakker, 2010).

Como resultado, en el Estado Español, la regulación atribuyó más competencias a los ayuntamientos (responsabilidades). En la ley de Obras Públicas de 1877 se establece el abastecimiento como un servicio municipal y en la Ley de Aguas de 1879 el abastecimiento de agua se regula como prioritario. Desde el siglo XX se regula la necesidad de control sobre las tarifas, asegurar la calidad y la continuidad, la obligación de atender a todos los barrios de las poblaciones o la necesidad de desarrollar una planificación completa esto conlleva la municipalización durante la década de

16 El movimiento higienista marcó un punto de inflexión en muchas ciudades. La suma de un sector político de corte más universalista, desde el que se acuñaron conceptos como «conciencia sanitaria» o «política social» (Castro, 2005), promovieron, por un lado, la asunción por parte de los gobiernos municipales de la gestión del servicio, y por el otro, la reforma de la regulación de dicho servicio promovida por el movimiento higienista. Ambos factores favorecieron la tendencia hacia la municipalización del servicio de abastecimiento básico, debido a la noción de responsabilidad social de dichos sectores políticos y porque la incorporación de las nuevas medidas desalentó al empresariado del momento (Matés, 2014).

B CLIVATGE, número 8

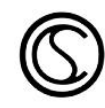


1920 (Heredia, 2014). De este modo los ayuntamientos acaban asumiendo la gestión del servicio y nos permite observar que se da un desplazamiento desde una gestión realizada por medio de actores privados (empresas) hacia una gestión llevada a cabo por la administración pública. Sin embargo, los actores privados no acaban de desaparecer puesto que los ayuntamientos, en el contexto español, en muchos casos fueron dotados de las competencias, pero no de los recursos necesarios para desarrollarlas.

\section{La remunicipalización del agua en Terrassa}

Terrassa es la tercera ciudad más grande de Catalunya ${ }^{17}$. El proceso de remunicipalización se inició a principios de 2014 con la constitución del grupo la Taula de l'aigua, quien impulsó todo el proceso que culminó oficialmente el 10 de diciembre de 2018, a través de la constitución de una entidad pública empresarial local (EPEL) acabando así con una gestión privada de más de un siglo y con la constitución del OAT el 10 de febrero de 2019.

17 Según la información consultada en el Institut d'Estadística de Catalunya (IDESCAT).
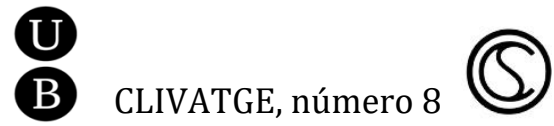
DOI: $10.1344 / C L I V A T G E 2020.8 .4$

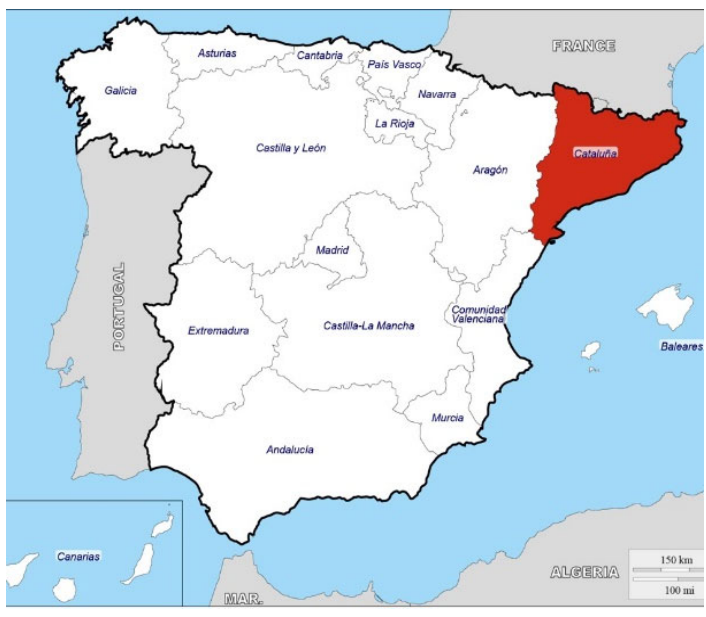

Mapa de la Península Ibérica. Fuente Google.

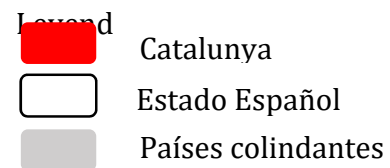

CLIVATGE $8 \mid \mathbf{1 6 3}$

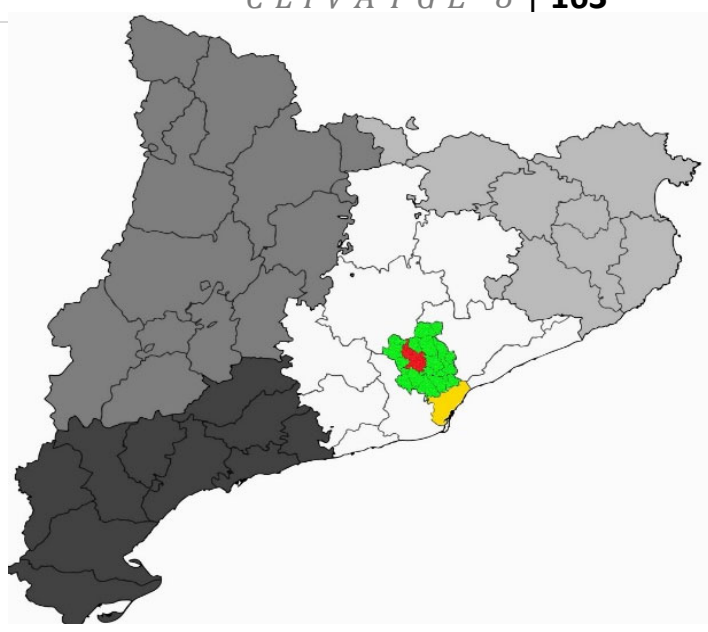

Mapa de Catalunya. Fuente: Elaboración propia Levenda:

Comarca del Barcelonès

Comarca del Vallès Occidental

Ciudad de Terrassa

Figura 1 Mapas de situación. Catalunya dentro del Estado Español (izquierda) y de Terrassa dentro de Catalunya y en relación con Barcelona (derecha)

Los debates de la Taula de l'aigua giraban en torno los nuevos comunes y la necesidad de extraer el agua de la lógica de mercado. De ahí que para ellos la remunicipalización significara trabajar para promover el cambio de modelo de gestión del agua municipal. Sus propósitos fueron la gestión directa del servicio y la democratización de las instituciones municipales a través de fórmulas que ampliasen la participación de la ciudadanía en los espacios y procesos de toma de decisiones. La remunicipalización era un mecanismo para ampliar el alcance democrático de las estructuras institucionales y el agua para repensar el carácter del 
municipio como una institución social (Calle y Vilaregut, 2015). Un espacio que engloba el conjunto de otras institucionalidades y redes, permitiendo la incorporación de la importancia de los derechos humanos y sociales y el lugar que debe ocupar la ciudadanía dentro de estas estructuras.

Durante los años 2012-2013 se vivió en la ciudad una situación de emergencia social con un aumento de cortes en los suministros fruto de los efectos de la Crisis de 2008. Ante esta situación la Taula de l'aigua de Terrassa propuso unos principios fundamentales sobre los cuales cimentar el edificio del nuevo servicio de agua. El resultado fue el documento La Remunicipalización del agua en Terrassa. Propuestas para la reversión del servicio y por una gestión directa, con participación ciudadana y transparencia 18. La propuesta la elaboraron a partir del diagnóstico en torno los aspectos del servicio que hasta finales de 2018 se había dado en Terrassa. Criticaban sobre todo el asalto que se ha había llevado a cabo sobre los bienes comunes, los supuestos beneficios de la gestión indirecta (privatizada) y los mecanismos de gestión privada como parte de los impedimentos para la participación cualitativa en la toma de decisiones. Con ello nos indicaban cuáles deberían ser los elementos constitutivos del nuevo servicio partiendo de los principios que debía organizar la gestión del agua. Estos eran el derecho al agua como Derecho Humano, con control

18 Se colaboró en dicho documento en el apartado inicial de contextualización al servicio de abastecimiento y su origen, así como a la remunicipalización de los servicios de agua en distintas partes del mundo, para completar todo el análisis posterior que sustenta toda la propuesta de la Taula de l'aigua.

B CLIVATGE, número 8

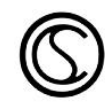


ciudadano desde criterios de sostenibilidad ecológica en términos de cuidado y que finalmente han quedado tipificados en un listado de trece principios ${ }^{19}$ (Reglament de l'observatori de l'Aigua de Terrassa, 2018: 6-7).

\subsection{Terrassa y el agua}

El proceso de remunicipalización del agua en Terrassa estuvo cruzado por muchos aspectos. Planas y Martínez (2020) destacan tres momentos clave: la concesión de 1941, momento en que se concedió la concesión administrativa de explotación del servicio de abastecimiento de agua a la compañía Mina Pública de Aguas de Terrassa, S.A. por un periodo de 75 años, el surgimiento de la Taula de l'Aigua de Terrassa y su labor para impulsar la recuperación del servicio y la constitución de la OAT, A pesar de la fuerte presión de los lobbies (Planas y Martínez, 2020).

Para Bagué (2020: 276-304) la importancia del proceso de Terrassa radica en que permite analizar la relación existente entre manejo del agua y modelo político y social, así como los cambios sucesivos de las fuentes de captación. Desde esta perspectiva, el caso de Terrassa permite distinguir tres momentos clave que lo muestran. En este primer período la organización del manejo y

${ }^{19}$ principio de derecho al acceso, el principio al precio justo, el principio de servicio público, principio de calidad del agua, principio de sostenibilidad del ciclo integral del agua, principio de nueva cultura del agua, principio de trabajo en red, principio de participación ciudadana, principio de transparencia, principio de fiscalización y auditoría externa, principio de sostenibilidad financiera, principio de gestión sostenible, eficaz y eficiente del servicio y principio de plena recuperación e internalización de los costes

B CLIVATGE, número 8

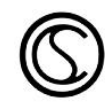


gobierno del agua se articulaba en torno diferentes fuentes de derecho y diversidad de actores en un sistema híbrido de instituciones y jurisdicciones superpuestas, desde reglas consuetudinarias hasta leyes estatales pre modernas (Roth et al., 2005, en Grau, 2017); y un marco institucional cambiante debido a la constante negociación de derechos (Grau, 2017). En la práctica, las aguas se manejaban mediante leyes locales en las que lo estipulado en las constituciones se combinaba con las reglas consuetudinarias (Grau, 2017).

El segundo periodo que va desde el siglo XIX hasta la primera mitad del siglo XX es donde se concentran los cambios estructurales a nivel de organización, responsabilidades y modificaciones en las formas de abastecimiento y distribución. Es el momento de la Revolución Industrial y con ella, la fundación de la Sociedad de la Mina Pública de Agua de la Ciudad de Terrassa constituida el 17 de marzo de 1842. Su creación tenía el objetivo de suplir las necesidades hídricas de la industria textil, que de rebote comportó las bases del servicio domiciliario a los habitantes de la ciudad. A tales efectos el 14 de abril de 1842 el Ayuntamiento de Terrassa aprobó las condiciones de la cesión a la Sociedad de la Mina Pública de Agua de la Ciudad de Terrassa de las Aguas de su propiedad, así como la construcción de la nueva mina y las Instalaciones necesarias (Ayuntamiento de Terrassa, 2018, Pastallé y Solé, 2002). De este modo, el Ayuntamiento cedía a la empresa la propiedad del agua con todos sus títulos y derechos a cambio de ciertos compromisos.

Con su creación, la administración pública delegaba y traspasaba sus responsabilidades, el control y la toma de decisiones a la

B CLIVATGE, número 8

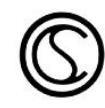


empresa extrayéndolo del espacio público colectivo de gobierno alrededor del agua en todas sus dimensiones, hacia la Sociedad de la Mina Pública de Agua de la Villa de Terrassa, una empresa particular. Esto se tradujo en un alejamiento de la dimensión social y pública del agua desde la población hacia el espacio empresarial, centralizado y aislado. El aumento de las necesidades de agua para la actividad industrial (basada en el vapor) necesitaba captar más agua acompañado de innovación tecnológica asociada que se traduce en una nueva comprensión y estructuración del sistema de distribución público. Un cambio en las formas de captación, infraestructura y distribución que va asociada a formas de acceso y derechos múltiples asociados a la nueva relación con el agua. Así se concretó un cambio en la concepción del agua y de la amplitud de sus usos - y actores - reduciendo de forma notable su significado a la distribución para la industria textil y consumo doméstico.

Supuso un cambio tecnológico, social e institucional. Un salto cualitativo en complejidad tecnológica que inició una tendencia centralizadora de la gestión y del suministro. Una centralización en torno la dimensión tecnológica de la asunción y la organización de la gestión de la red que se asocia al cambio en la autoridad, que desde ese momento se asocia al conocimiento sobre el agua y su gestión, y determina los mecanismos de toma de decisiones. Así pues, este cambio de autoridad supuso un cambio en la legitimidad, desde el espacio de las instituciones de gobierno hacia la empresa que se erigió como el espacio legítimo de referencia. Esto sucedía al mismo tiempo que se producía un nuevo marco a nivel estatal y el despliegue de las nuevas regulaciones en materia de agua (Leyes de

B CLIVATGE, número 8

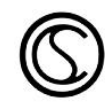


aguas de 1833 y 1866) y los nuevos ayuntamientos constitucionales.

El último periodo establecido es el correspondiente a la segunda parte del siglo XX hasta el fin de la concesión. Periodo que se caracteriza por el cambio de Sociedad de la Mina Pública de Agua de la Ciudad de Terrassa a Mina Pública de Aguas de Terrassa S.A. hasta la finalización del contrato de concesión de 2016. En este período encontramos, por un lado, el cambio en el punto de captación y el otorgamiento de la concesión que finalizaba en 2016 $y$, por el otro, las tensiones relacionadas con los acuerdos históricos en la relación entre el Ayuntamiento de Terrassa y Mina Pública de aguas de Terrassa S.A. que se vivieron en la ciudad cuando la lucha por la remunicipalización se inició 20 .

Por lo tanto, se detectan tres momentos en la historia de la ciudad que atraviesan su rumbo y que terminan incidiendo en al agua. Primero, el cambio de la ciudad hacia la industrialización y sus repercusiones en las estructuras de la ciudad, que hacen posible la llegada del servicio de abastecimiento a la ciudad como un servicio derivado del impulso industrial, y llevado a cabo mediante las alianzas de las élites que ocupaban los tres espacios clave: el político, económico y social. Segundo, la restitución de estas relaciones con el gobierno local que fue después de la Guerra Civil (1936-1939) y que dio pie a la concesión que acaba de terminar y que reafirmaba de nueva cuenta las élites locales ante las

20 Por medio de la prensa se puede hacer el seguimiento de la tensión que suposo la remunicipalización del servicio en la ciudad.

B CLIVATGE, número 8

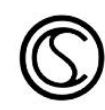


decisiones relacionadas con el agua. Y finalmente, la llegada a la alcaldía de un gobierno democrático que tenía fuertes lazos con estos sectores de la ciudad, buscando proteger el estatus de Mina Pública de Aguas de Terrassa SA como empresa de referencia en la ciudad. En el agua podemos observar de forma clara el funcionamiento de la red constituida por las élites burguesas de la industria textil y sus mecanismos de control con absoluta claridad.

\subsection{El servicio en el momento de la remunicipalización}

La Taula de l'aigua de Terrassa llevó a cabo un análisis de este servicio básico y esencial a partir del Derecho Humano al agua y su desmercantilización como un común que debía ser recuperado. De este análisis se substraen aspectos de carácter más técnico que caracterizan este servicio, junto con otros de índole sociopolítica.

Detectaron, por un lado, que había dificultades vinculadas a la relación entre organismos públicos $\mathbf{y}$ actores privados (empresas concesionarias) poniendo de manifiesto que existe una divergencia inherente en los intereses propios de cada uno. Una lógica mercantil donde el actor privado tiene interés de lucro y no vocación de servicio, prácticas de monopolio, corrupción con dejes clientelares vinculados al enriquecimiento y lucro personal por medio de la prestación de un servicio público y la comprensión del ciudadano (usuario) como cliente. Y el otro, el reflejo de los problemas estructurales de la concepción y gestión de lo público que dio pie a los debates entre público (gestión directa) y privado (gestión indirecta). Debates que advierten de las limitaciones inherentes a la comprensión y estructuración del propio servicio y que se expresan en la crítica y la denuncia sobre

B CLIVATGE, número 8

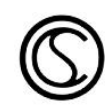


déficit democrático, la transparencia (todos los niveles de transparencia que se detectan) y la toma de decisiones.

En lo referente a la relación entre público y privado, el análisis es amplio y los aspectos muchos. Aquí destacamos dos. Los efectos de la situación de monopolio del sector ${ }^{21}$ que, junto con la falta de recursos y la debilidad institucional en la que se encuentra la administración pública, favorecen las puertas giratorias y relaciones clientelares con políticos, con una gran falta de transparencia y un déficit democrático estructural que favorece la vulneración del Derecho Humano al agua. Esto se debe a que los operadores privados se han caracterizado por moverse por el afán de lucro y el rendimiento económico, hecho que ha motivado, según la Taula de l'aigua 22 , falta de interés por el mantenimiento de la red y del servicio, como un comportamiento histórico de los operadores privados. Además, Cadevall (2017) advierte que la recuperación de un servicio es muy compleja y el articulado lo dificulta sobremanera hecho que pone de manifiesto el interés real en mantener actores del sector privado en el espacio de provisión de servicios públicos (Cadevall, 2017).

También se detectó que el servicio estaba estructurado desde premisas empreserializadas y gerenciales. Este punto se conecta directamente con los debates que cruzan la visión mercantil del

\footnotetext{
21 La situación de monopolio transnacional se ha hecho pública en los últimos años, pero hasta el momento se daba sin más repercusión.

22 El análisis realizado por las personas que conforman la Taula de l'aigua de Terrassa, se mueve entre los datos bibliográficos, la casuística de otras poblaciones y la situación particular de Terrassa.
}

B CLIVATGE, número 8

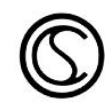


agua y el déficit democrático. Esta realidad se da tanto bajo régimen de gestión directa como indirecta y es lo que de manera más fuerte relaciona la remunicipalización con la democracia y la transparencia, dando pie al debate en torno al cómo (modelo) y no sólo en el quién y qué (titularidad y objeto). El peso de los valores neoliberales contribuye a consolidar una estructura en la que los objetivos del grupo empresarial y los criterios para la toma de decisiones son ajenos al lugar donde impactan. Esto favorece la disminución de espacios de ejercicio democrático vinculados al territorio y el municipio ${ }^{23}$. Esta crítica sobre el déficit democrático se centra en el hecho de que no hay vías por medio de las cuales la ciudadanía pueda formar parte del gobierno del servicio, ya sea en gestión directa o indirecta (Varo et al., 2017).

Siguiendo a McDonald (2013) podemos aducir que los principios empresariales en torno a este servicio están relacionados con una estructura técnico-política de toma de decisiones que se da en espacios reducidos poco claros y con escasos mecanismos de rendición de cuentas. En concreto, el peso de las decisiones

23 El tema que se analiza es altamente dinámico, por lo que se hace necesario plasmar aquí, que, en el invierno de 2019, AGBAR hizo la presentación pública de un consejo asesor ciudadano como propuesta de órgano de participación. Se sabe poco de su composición, funciones y objetivos, pero es importante porque muestra que AGBAR (grupo Suez) está buscando maneras de actualizar el modelo y está haciendo un seguimiento al peso del eje de la práctica democrática, lo que es un indicativo de la profundidad de los temas que se están cruzando e imbricando dentro del gobierno del agua. Ello contribuye aún más a comprender que el agua está siendo uno de los campos de batalla del cambio social e institucional. 
relativas al servicio recae en el Consejo de Administración de la empresa y el gerente. Esta estructuración es parte del déficit democrático que se señala dados los mecanismos de toma de decisiones que se articulan, puesto que son opacos y favorecen la falta de transparencia. Ello contribuye a la práctica naturalizada de las puertas giratorias.

La concepción empresarial del servicio que caracteriza, hasta el día de hoy, el modelo hegemónico de gestión vigente queda claramente expuesta cuando las personas son tratadas como clientes, hecho que repercute en la relación entre los actores, puesto que, dentro de este esquema, no se contempla que haya necesidad de comunicación entre clientes y responsables del servicio. Este punto es importante porque supone la nulidad de cualquier derecho que la ciudadanía pudiera ejercer como tal en tanto que, al quedar fuera, no puede reclamar ninguna obligación o responsabilidad más allá de la propia entre consumidor-empresa (Bagué, 2016). El diálogo sobre la gestión queda entre el ente público y la empresa (como proveedora del servicio). Es dentro de este modelo que se sitúan los argumentos expuestos por espacios como la Taula de l'Aigua acerca de su interés en ser reconocidos como ciudadanía en un marco de gestión pública directa y de la importancia de cambiar la concepción empresarial de lo público para transitar hacia la concepción comunal de lo público.

\subsection{Recuperación del servicio y el control sobre la vida. El control ciudadano y la toma de decisiones}

La suma de los factores expuestos es lo que ha llevado a las plataformas por la remunicipalización, como la Taula de l'Aigua de

B CLIVATGE, número 8

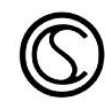


Terrassa, a exponer la necesidad de desarrollar instrumentos y mecanismos de control junto con la necesidad de abrir el debate en torno al modelo de gestión. La recuperación del servicio parte de la necesidad de recuperar el control y de este modo se abre la puerta a la construcción del común desde las formas de gobierno, la concepción del agua en su relación con el territorio, introduciendo una visión amplia y compleja de ella.

Una de las aportaciones importantes es el hecho que el DHAS ha pasado a ser comprendido como un derecho colectivo y una responsabilidad propia de la administración pública y ello justifica la importancia del control sobre la totalidad del servicio y su imbricación con el ejercicio de responsabilidad y transparencia del que debe formar parte la ciudadanía. Un control que pasa por el control de la información, pero también de la toma de decisiones, como vías para el control sobre la vida (por parte de la ciudadanía). Este aspecto muestra que los planteamientos que aparecen como críticas al servicio, en realidad son una muestra de sus propios límites y se relacionan con una crisis del propio sistema político y social, representativo, del que el servicio de abastecimiento aparece como su reflejo (Bagué, 2020). Una respuesta, que como coinciden en detectar los distintos autores (Subirats y Rendueles, 2016; Laval y Dardot, 2015; Harvey, 2013), es una respuesta a la deslocalización, la globalización y lo que se percibe como un capitalismo sin escrúpulos que se ejecuta por vía de las instituciones actuales.

Por ello el ejercicio de este control pasa por una mayor imbricación entre sociedad y espacio político de gobierno en tanto que la afectación de las decisiones afecta al conjunto de los habitantes,

B CLIVATGE, número 8

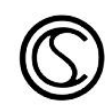


hecho que se relaciona con el común puesto que implica la existencia de cierta obligación de reciprocidad ligada al ejercicio de responsabilidad pública (Laval y Dardot, 2015) en el que el municipio es el espacio de referencia, en una recuperación de su sentido etimológico.

Y entonces ya sólo haría falta añadir inevitablemente una novedad: articular la participación ciudadana para eliminar la posibilidad de corrupción y asegurar la rendición de cuentas y la transparencia. Y esto sólo se puede hacer con legitimidad contando con la propia ciudadanía, no regulando desde arriba (Giménez, 2017).

De este modo, la propuesta de la Taula de l'aigua supone una línea de trabajo dirigida a fortalecer las instituciones, pero desde la praxis instituyente del común, y que, a fuerza, debe expresarse con formas de organización en torno la toma de decisiones. A partir de aquí se abre la ventana a indagar sobre mecanismos para generar política pública siendo la remunicipalización una manera de recuperar el control sobre la vida en la tensión entre capital y vida (Pérez, 2014, Gil, 2011), abriendo la puerta a la construcción del agua como común.

Posicionamiento que quedó expuesto claramente cuando la Taula de l'aigua de Terrassa en la Jornada Agua Bien Común dijo que este proceso había que entenderlo "en complicidad y realimentado desde un proceso más amplio de construcción social (...) que no se puede entender al margen del impulso social que supuso el 15M" (Martínez, 2017).

Es en este espacio que se abre una tensión y un debate entre el sentido de la participación y el anhelo por renovar las formas de gestión ahondando y buscando en el marco de las políticas públicas,

B CLIVATGE, número 8

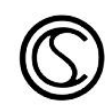


fórmulas de participación que se acerquen a la democracia directa. Han pasado varios años y las cosas han cambiado de forma vertiginosa, y en este sentido la demanda de más importancia a la ciudadanía como sujeto que propone, en tanto que sujeto político, y la emergencia del referente de los comunes, permiten retomar las tesis de Macpherson (1977) y Aguiar y Navarro (2000) para ahondar en estas afirmaciones en busca de propuestas concretas. (Bagué, 2020: 453). Esto se ha traducido en un anhelo por querer recuperar formas de toma de decisiones, que, aunque no siempre se han vivido en la práctica, se perciben como válidas y necesarias para retomar el camino hacia una sociedad más democrática.

En este intento de recuperar el control sobre los procesos han tomado fuerza en el proceso de Terrassa sobre cómo pensar en crear concepciones de control ciudadano y toma de decisiones que incorporen la rendición de cuentas como parte del entramado de lo que ya es denominado como gobierno del servicio y que se encuentra estrechamente vinculado al espacio institucional municipal, dotando de importancia al municipio como espacio de referencia (Bagué, 2020: 453). En el caso de Terrassa este proceso culminó con la creación del OAT.

Comunalizar la institución como motor para repensar la institución y la institucionalidad. En esta búsqueda hacia una transformación profunda de las instituciones se produce un salto desde la participación que busca otras formas de organizar la práctica en torno la idea de democracia. Por este motivo, a través del común, se articulan formas de organización colectiva que no necesariamente responden a los cánones de los comunes rurales u organización comunal de los recursos. Más bien, se trata de indagar

B CLIVATGE, número 8

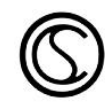


para implementar formas de gobierno más colectivas $\mathrm{y}$ entrelazadas. Se trata de comprender el común como un elemento articulador de lo público que a fuerza debe expresarse con formas de organización en torno la toma de decisiones (Bagué, 2020: 460).

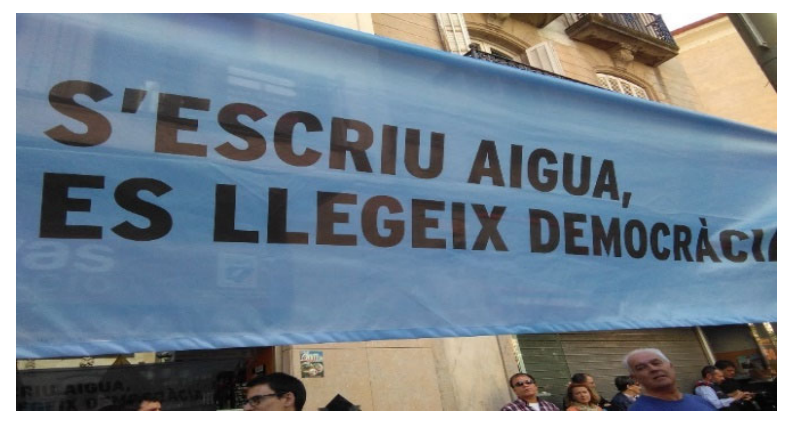

llustración 2 Foto de una de las pancartas de la manifestación del 19 de marzo de 2017 en Terrassa. Fuente: Edurne Bagué.

El Control ciudadano surge como una herramienta para que la ciudadanía pueda ejercer labores de vigilancia y seguimiento del cumplimiento de las obligaciones que los representantes políticos tienen como compromiso y objetivo (Galán, 2015). Por su parte, Arnstein (1969) le atribuía más capacidad decisoria en tanto que se encargaba a las comunidades (barrios, vecinales, etc) el control sobre el desarrollo de programas sociales, pero, no se trascendía de forma estructural y se acababa traduciendo en una externalización de responsabilidades desde la entidad pública hacia la comunitaria. Por lo tanto, por un lado, es una medida que surge de los problemas de distanciamiento $\mathrm{y}$ falta de compromiso político de los

B CLIVATGE, número 8

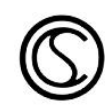


representantes políticos con la ciudadanía. Y, por el otro lado, no se plantea como una propuesta que ponga en duda sea el sistema representativo actual, ni en sí la organización institucional. Se limita a detectar si hay malas prácticas a las que hay que dar una respuesta para erradicarlas. Esta respuesta es la vigilancia por parte de la ciudadanía por medio de la herramienta de control ciudadano (Bagué, 2020: 506-507).

Ahora bien, cuando la Taula de l'aigua, junto con los técnicos municipales, emprendió el camino hacia la concreción del común por medio del OAT superaron estas definiciones y competencias como fruto de los debates profundos mantenidos. De estos debates surgió la comprensión del control ciudadano como una herramienta a través de la cual trascender hacia la concepción de otras formas de gobierno. De este modo se abre una vía por la que se establece la conexión con el principio de común y el concepto de gobierno abierto. Este aporte a la herramienta del control ciudadano surge después de detectar que existe una relación entre el control y las prácticas democráticas de gobierno (Bagué, 2020: 507).

No votar no cambia las relaciones que se establecen. Hay que cambiar la dinámica. No ir y arrambar con el poder del voto, sino desmontar estas relaciones.

El problema será que los políticos muchas veces dirán/aprobarán cosas con la guerra de los votos (decidirán a partir de lo que los beneficie de cara al electorado, independientemente de si en algunos momentos las decisiones deben ser poco guays de cara a fuera.

B CLIVATGE, número 8

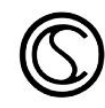


Con la guerra de los votos, nos olvidamos de diluir la idea de que el voto sea el que toma las decisiones sobre la empresa (...) la solución pasa por extraer los marcos estipulados y de la dinámica de los votos.

¿Cómo lo haces si tienes un voto? De ¿qué sirve la ciudadanía? (...) en el fondo te lleva a la misma ecuación: si no se desbloquea la incorporación de las cosas que vienen de abajo ${ }^{24}$.

Así es como el control ciudadano aparece como una vía para acceder a la toma de decisiones. Hay un interés en asumir responsabilidades y capacidad de incidencia política. Se buscaba trabajar en clave de transformación social creando nuevas lógicas institucionales, fomentar el ejercicio de la co-responsabilidad como algo colectivo y base para una nueva institucionalidad. Hecho que lo acerca a las prácticas de comunalización (Bagué, 2020: 511-512). Desde esta perspectiva el control ciudadano se sitúa en el campo de la toma de decisiones como algo imbricado a un proceso que se da en el marco de una estructura, de tal modo que el eje desde el que se generan los debates cambia el lugar. De este modo se sitúa la toma de decisiones en los niveles de colectivo y constitucional estipulados por Östrom (2011), en este caso, del servicio de abastecimiento, tal y como queda recogido en el propio Reglamento del OAT. Así pues, la toma de decisiones se concreta en la importancia que tienen los espacios donde se genera y se piensa la política hídrica municipal y explica la importancia de los GT encargados de trazar estos delineamientos más estructurales de los

24 Extractos de material recogido en campo.

B CLIVATGE, número 8

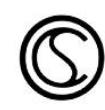


que se desgranarán los aspectos concretos sobre los cuáles decidir. Esto es la diferencia entre la dimensión de gobierno, donde se decide y crea a partir de los principios y objetivos, y la de gestión, donde se ubican los aspectos puramente técnicos.

\section{Algunos apuntes finales}

El detonante para el surgimiento de la remunicipalización es hacer frente al neoliberalismo. En el camino se ponen sobre la mesa problemas más profundos extralimitan al neoliberalismo y que llevan directamente a los pilares mismos del modelo de sociedad. Su origen en AL a principios de los 2000 supuso una posibilidad de abrir procesos constituyentes de claro signo Decolonial y de cuestionamiento profundo a la globalización.

En el marco del Estado Español y Catalunya, la Remunicipalización tiene que ver con las fuerzas que impulsan cambios más profundos (que son vehiculados por medio de servicios como el del agua urbana) cambios relacionados con ¿Qué se entiende por lo público? Y por lo tanto quién y cómo se toman las decisiones. Lo que implica la reformulación de las estructuras en torno al ejercicio del gobierno (servicio o político) y de procesos de toma de decisiones. En este punto es donde toma sentido la remunicipalización como una práctica de comunalización.

Para la Taula de l'Aigua el municipio es el espacio de gobierno que fue expoliado (cercado) en eso está el servicio, y por esto no se busca una asunción del servicio liberando a la administración de su responsabilidad. Sino que la ciudadanía forme parte del gobierno del servicio, por la cualidad inalienable del agua y porque el 
municipio es un espacio de lo público a recuperarse desde el común (autogobierno).

En el caso de Terrassa se puede ver cómo la ciudadanía ha conseguido ser un actor propio con propuesta con vistas a trabajar juntamente con el espacio institucional. Y la propuesta de Terrassa supone la puerta de entrada a una nueva concepción de la gestión y el gobierno del agua en la ciudad que puede servir para ir más allá de la propia ciudad, sirviendo de ejemplo a futuras experiencias.

La suma de factores muestra que la municipalización de un servicio, como en este caso el agua, puede comportar transformaciones de gran calado que trastocan los pilares básicos y profundos de las relaciones sociales y del poder local, a partir de las cuales se ponen en escena debates profundos como los que abre la Taula de l'aigua, en torno a democracia, cuál es el papel de las instituciones, quién son las instituciones, es decir, ¿cómo se construye común en el municipalismo urbano post industrial? ¿Cuál es el papel de las instituciones y quiénes son las instituciones?

La remunicipalización del servicio urbano de agua se ha presentado como un espacio que permite el seguimiento de los debates en torno la democracia, las instituciones y permite la detección de aquellos elementos en los que se concretan los cambios, que son a su vez el reflejo de los principios y valores sociales emergentes. En ese momento el contexto en Catalunya y el Estado Español se presentaba como un espacio una posible transición social hacia nuevas formas de organización política para la toma de decisiones. Todo ello ha sido el motor de la propuesta de la Taula de l'Aigua de Terrassa.

B CLIVATGE, número 8

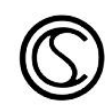


Todo ello ha permitido analizar el espacio en el que se da el encuentro entre la noción de común, las instituciones ya existentes, la democracia, el municipio y la importancia de las personas como elementos que estructuran la batalla contra el expolio de los espacios de vida que supone el neoliberalismo. Permitía presentar el espacio local como un nodo de relaciones que imbrican todos los niveles, de tal modo que se podía partir de lo local como espacio territorializado que tiene sentido para las personas y en el que inciden de forma concreta las decisiones tomadas en espacios deslocalizados y abstractos. Esto tenía que ver con el escenario de Crisis, donde en la cotidianidad de la vida era dónde se concretaban las consecuencias de las decisiones tomadas en clave global (la externalización de los costos), a lo que se le agregaba el hecho del agua, como algo de carácter vital.

\section{6.- Bibliografía}

Agamben, Giorgio (2010): "Nota preliminar sobre el concepto de democracia", en Democracia en suspenso, ediciones Casus Belli, traducción de Tomás Fernández Aliz y Beatriz Eguibar, ISBN: 978-84-937828-2-5, Madrid.

Aguiar, Fernando y Navarro, Clemente (2000): "Democracia y participación ciudadana en los municipios: ¿Un mercado político de trastos?" Reis: Revista española de investigaciones sociológicas, ISSN 0210-5233, № 91, 2000, pags. 89-114. 1. $10.2307 / 40184276$.

Arnstein, Sherry (1969): 1969 "A ladder of citizen participation", AIP Journal, july.

B CLIVATGE, número 8

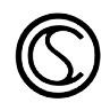


Badia, Eloi y Subirana, Moises (2015): “Una escletxa que s'obre pas al monolític paisatge català", Un futur per l'aigua pública. L'experiència mundial de la remunicipalització, Transnational Institute (TNI), [Coord] Kishimoto, Lobina, E, S, y Petitjean, 0., Public Services International Research Unit (PSIRU), Multinationals Observatory, Municipal Services Project (MSP) and the European Federation of Public Service Unions (EPSU): Amsterdam, London, Paris, Ciudad del Cabo y Bruselas, ISBN 978-90-70563-52-3

Bagué, Edurne (2016): "Hacia una cultura y gestión democrática del agua", $X$ Congreso Ibérico, Fundación de la Nueva Cultura del Agua, Valencia.

(2017): "La remunicipalización del servicio de abastecimiento urbano de agua: instituciones y común", Revista de Antropología Social, Universidad Complutense de Madrid, Vol. 26, No 2, págs. 427-448.

(2018) "El papel de los elementos sociales que contribuyen a la tendencia remunicipalizadora en España y Catalunya" The struggle for democracy in Spain: grassroots initiatives to defend essential water services as a common good José Esteban Castro (Ed.) Edurne Bagué (Org.), Thematic Area Series Thematic Area 3 Urban Water Cycle and Essential Water Services, WATERLAT-GOBACIT NETWORK Working Papers Thematic Area Series - TA3 - Vol 5 № 1/ 2018 Newcastle upon Tyne and Mexico City, March.

(2019) Remunicipalització, participación i democràcia. Anàlisi i eines per a noves propostes de govern de l'aigua a Catalunya. Enginyeria sense Fronteres. 
(2020) La remunicipalización del agua en Terrassa (Catalunya). La lucha de la Taula de l'Aigua por un modelo de gestión del agua como común (2014-2019). Tesi doctoral, Directora: Dra. Lourdes Romero Navarrete,Centro de Investigaciones y Estudios Superiores en Antropología Social, Ciudad de México, Mèxico.

Bakker, Karen (2010): Privatizing water. Governance failure and the world's urban watercrisis. Nueva York, Cornell University Press.

Beltran, Oriol y Vaccaro, Ismael (2017): "Los comunales en el Pirineo Central. Idealizando el pasado y reelaborando el presente" en Revista de Antropología Social de la Universidad Complutense de Madrid 26(2) 2017: 235-257, ISSN: 1131-558X

Brown, Wendy (2010): "Ahora todos somos demócratas" en Democracia en suspenso, ediciones Casus Belli, traducción de Tomás Fernández Aliz y Beatriz Eguibar, ISBN: 978-84937828-2-5, Madrid.

Cadevall, Marc (2017): “La gestió i el govern del servei. Instruments tècnics, administratius i econòmics. Selecció del sistema de gestió. L'informe preceptiu exigit per la LRSAL Model de Pla econòmic i financer. Indicadors de gestió", Curs sobre Cicle Urbà de l'aigua, Federació de Municipis de Catalunya, 9 de mayo.

Calle, Angel y Vilaregut, Ricard (2015): Territorios en Democracia. El municipalismo a debate, Icaria, Barcelona, ISBN 978-849888-635-1 
Castro, José Esteban (2005): “Agua y gobernabilidad: entre la ideología neoliberal y la memoria histórica" en Cuadernos del CENDES, año 22, número 59, tercera época, mayo-agosto.

Caton, Steven y Orlove, Benjamin (2010): "Water Sustainability: Anthropological Approaches and Prospects", Annual Review of Anthropology, 39:401-15, This article's doi:10.1146/annurev.anthro.012809.105045, 00846570/10/1021-0401\$20.00

Ceceña, A.E, (2004); La guerra por el agua y por la vida, una construcción comunitaria frente al neoliberalismo del Banco Mundial, Cochabamba.

Congost, Rosa (2007): Campos cerrados, debates abiertos Análisis histórico y propiedad de la tierra en Europa (siglos XVI-XIX) [Eds.] Rosa Gongost y José Miguel Lana, Universidad Pública de Navarra: Nafarroako Unibertsitate Publikoa Fotocomposición: Pretexto Imprime: Ona Industria Gráfica Depósito Legal: NA-2149/2007, ISBN: 978-84-9769-189-5

Chamoux, Marie Noëlle y Contreras, Jesús (1996) “Introducción” en La Gestión Comunal de recursos. Economía y poder en las sociedades locales de España y América Latina, [Ed.] Chamoux, M.N. y Contreras, J, pp. 11-47, Barcelona: IcariaInstitut Català d'Antropologia.

Federici, Silvia (2010): Calibán y la bruja, Calibán y la bruja. Mujeres, cuerpo y acumulación originaria, Traducción: Verónica Hendel, Leopoldo Sebastián Touza, ISBN: 978-84-96453-517.

Galán, Rodrigo Edmundo (2015): "El control ciudadano de los representantes y la rendición de cuentas". <i

B CLIVATGE, número 8

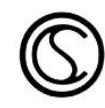


xmlns="http://www.w3.org/1999/xhtml">Revista de Derecho, $</ \mathrm{i}>$ (43), undefined-undefined. [fecha de Consulta 29 de Agosto de 2019]. ISSN: 0121-8697. Disponible en: <a xmlns="http://www.w3.org/1999/xhtml" target="_blank" href $="$

http://www.redalyc.org/articulo.oa?id=851/85138494010 ">

http://www.redalyc.org/articulo.oa?id=851/85138494010 $</ a>$

Garcés, Marina (2013): Un Mundo común, Edicions Bellaterra, Barcelona.

Gil, Silvia L. (2011): Nuevos feminismos. Sentidos comunes en la dispersión, Traficantes de Sueños, Madrid.

Giménez, Sonia (2017): Terrassa en proceso hacia un nuevo modelo de gestión del agua: hacia la cogestión entre la administración local y la ciudadanía. Ensayos para una nueva democracia. (inédito), Terrassa.

Gomà, Ricard y Blanco, Ismael (2016): El municipalisme del bé comú, Icaria, Barcelona, ISBN: 9788498886993

Grosse, R, Santos, C, Taks, J y Thimmel, S (2006); Las canillas abiertas de América Latina II, La lucha contra la privatización del agua y los desafíos de una gestión participativa y sustentable de los recursos hídricos, Casa Bertolt Brecht, Montevideo, Uruguay.

Grau, Mar (2017): Adaptation before Anthropogenic Climate Change: A Historical Perspective on Adaptation to Droughts in Terrassa (1600-1870s, NE Spain), PhD Dissertation, Dir. Dr. Iago Otero Dr. Victoria Reyes-Garcia Dr. Erik Gomez- 
Baggethun. Ph.D. Programme in Environmental Science and Technology Institut de Ciencia i Tecnologia Ambientals, ICTA y Universitat Autonoma de Barcelona, UAB; March.

Hall, David (2005), "Introducción" en Por un Modelo Público de Agua. Triunfos, Luchas y Sueños. Brid Brennan, Olivier Hoedeman, Philipp Terhorst, Satoko Kishimoto y Belén Balanyá (Eds.), Transnational Institute, Corporate Europe Observatory y El Viejo Topo. Disponible en: https://www.tni.org/archives/books/aguaintro.pdf

Hardt, Micheal y Negri, Antonio (2011): Commonwealth. El Proyecto de una revolución del común. Akal, ISBN: 978-84-460-32304, Madrid.

Harstrup, Karen (2013) "Water and the Configuration of Social Worlds: An Anthropological Perspective" en Journal of Water Resource and Protection 5, 59-66

http://dx.doi.org/10.4236/jwarp.2013.54A009. Published Online April 2013

(http://www.scirp.org/journal/jwarp).

Harvey, David (2013): Ciudades Rebeldes. Ediciones Akal, Madrid. Heredia, V.M (2014) Gestión privada y municipalización en el abastecimiento a la ciudad de Málaga. El «negocio» de las Aguas de Torremolinos (1860-1930). Tesis Doctoral, Universidad de Málaga, Facultad de Ciencias Económicas y Empresariales.

Herrero, Yayo (2011) "Golpe de estado en la biosfera: los ecosistemas al servicio del capital" en Investigaciones Feministas, vol 2 215-238, ISSN: 2171-6080 http://dx.doi.org/10.5209/rev INFE.2011.v2.38612 
(2015) "Apuntes introductorios sobre el Ecofeminismo" Centro de Documentación Hegoa, Boletín de recursos de información no 43, junio 2015, ISSN: 2255---369X,

http://boletin.hegoa.ehu.es/mail/37

IDESCAT

Jiménez, Carolina y Puello-Socarrás, José Francisco (2017): “Las disputas en torno a la común. Experiencias comunales de gobierno desde abajo como alternativas contrahegemónicas", Colección Estudios Técnicos para la construcción de la paz, Bogotá (Colombia), ISBN: 978-95856058-7-9

Kishimoto, Satoko, Lobina, Emanuele, Petitjean, Olivier (2015): Our public water future. The global experience with remunicipalisation. Transnational Institute (TNI), Public Services International Research Unit (PSIRU), Multinationals Observatory, Municipal Services Project (MSP) and the European Federation of Public Service Unions (EPSU): Amsterdam, London, Paris, Ciudad del Cabo y Bruselas.

Kishimoto, Satoko, Steinfort, Lavinia and Petitjean, Olivier (2020): Towards Democratic Ownership of Public Services, Edited by Satoko Kishimoto, Lavinia Steinfort and Olivier Petitjean. Published by Transnational Institute (TNI), Multinationals Observatory, Austrian Federal Chamber of Labour (AK), Canadian Union of Public Employees (CUPE), Danish Union of Public Employees (FOA), De 99 Van Amsterdam, The Democracy Collaborative (US), European Federation of Public Service Unions (EPSU), Ingeniería Sin Fronteras Cataluña (ISF), MODATIMA (Movement of defence of water,

B CLIVATGE, número 8

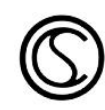


land and the environment, Chile), Municipal Services Project (MSP), the Netherlands Trade Union Confederation (FNV), Norwegian Union for Municipal and General Employees (Fagforbundet), Public Services International (PSI), Public Services International Research Unit (PSIRU), University of Glasgow (Scotland) and We Own It (UK). tni.org/futureispublic.

Langford, M y Khalfan, A. (2006) "Introducción al agua como derecho humano" en La gota de la vida: hacia una gestión sustentable y democrática del agua. Fundación Heinrich Böll, México.

Latour, Bruno (2005): Nunca fuimos modernos. Ensayo de antropología simétrica. Siglo XXI Editores, ISBN 978-9871220-85-4, Argentina.

Laval, Christian y Dardot, Pierre (2015): Común. Ensayo sobre la Revolución en el Siglo XXI, Barcelona: Gedisa.

Lobina, Emanuele (2015): "Introduction Calling for progressive water policies" en Our public water future. The global experience with remunicipalisation [Coord.] Kishimoto, Satoko, y Petitjean, Olivier, Published by Transnational Institute (TNI), Public Services International Research Unit (PSIRU), Multinationals Observatory, Municipal Services Project (MSP) and the European Federation of Public Service Unions (EPSU), Amsterdam, London, Paris,Cape Town and Brussels. ISBN 978-90-70563-50-9-48-7

Lobina, E.; Weghmann, V. and Marwa, M. (2019): “Water justice will not be televised: Moral advocacy and the struggle for transformative remunicipalisation in Jakarta". Water 
Alternatives 12(2): 725-748, www.water-alternatives.org Volume 12 | Issue 2

Macpherson, Crawford Brough (1977): La Democracia Liberal y su época, Alianza Editorial. Madrid.

McDonald, David (2013): “iLa remunicipalización funciona!” en Remunicipalización: El retorno del agua a manos públicas, Martin Pigeon, David A. McDonald, Olivier Hoedeman y Satoko Kishimoto, editores, Transnational Institute, Ámsterdam, ISBN 978-94-6228-049-6.

Matés, José Manuel (2009): "El servicio de abastecimiento de agua potable" en Historiografía sobre tipos y características históricas, artísticas y geográficas de las ciudades y pueblos de España. [Ed: Carmen Delgado, Luis Sazatornil, Germán Rueda, Ediciones TGD, Santander, ISBN 978-84-96926-31-8

2014 "Las empresas concesionarias de servicios de abastecimiento de aguas potables en España (1840-1940)" en Transportes, Servicios y telecomunicaciones ISSN 1578-5777, №. 26, 2014 , págs. 36-67

2016 "La regulación del suministro de agua en España: siglos XIX y XX" en Revista de historia industrial, ISSN 1132-7200, №. 61, 2016 (Ejemplar dedicado a: La regulación de los servicios públicos en España en perspectiva histórica), págs.15-48

Memòria Justificativa per la determinacio de la forma de gestió per la prestació del servei públic d'abastament d'aigua a Terrassa Comissió estudi per a la determinació de la forma de gestió del servei d'abastament d'aigua de Terrassa, Ajuntament de Terrassa, marzo 2018

B CLIVATGE, número 8

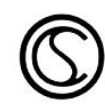


Montesinos, Lidia (2011): "Tierras comunales en Navarra: de bienes del común de los vecinos, a montes de utilidad pública", en el simposio Re-construyendo el territorio: de las formas de apropiación local a la participación en las nuevas políticas públicas, [Coords]: Jose J. Pascual Fernández (Universidad de La Laguna, ACA), Javier Escalera Reyes (Universidad Pablo Olavide, ASANA), Lugares, tiempos y memorias XXII Congreso de Antropología.

(2013) IRALIKU'K: La confrontación de los comunales. Etnografía e historia de las relaciones de propiedad en Goizueta, Tesis Doctoral, Universitat de Barcelona.

Observatorio Metropolitano de Madrid (2015): “L'aposta municipalista" en L'aposta municipalista de les bullangues a les lluites actuals pels municipis lliures a Catalunya, Observatorio Metropolitano de Madrid, Xavier Diez y Col·lectiu Víric. Editorial Virus. Barcelona.

Opazo, Daniel (2015): “Creating an Appropiating Urban Spaces The Public versus the commons: Institucions, Traditions, and Struggles in the Production of Commons and Public Spaces in Chile" en Moving Beyond State and market, Mary Dellenbaught, Markus Kip, Majken Bueniok, Agnes Katharina Müller, Martin Schwegmann (Eds.) Urban commons, Birkhäuser Verlag GmbH, Basel, ISBN EPUB 978-3-03821$661-2$

Östrom, Elinor (2011): "I. reflexiones sobre los bienes comunes", pp. 35-76 y "II. Una perspectiva institucional para el estudio de la autororganización y el autogobierno en casos de RUC", pp. 76-118, en El gobierno de los bienes comunes., FCE, México 
Pastallé, Pere y Solé, Miquel (2002); Mina Pública d'Aigües de Terrassa. Una empresa al servei de la comunitat, Fundació Mina, Terrassa.

Pérez Orozco, Amaia (2014) Subversión feminista de la economía. Aportes para un debate sobre el conflicto capital-vida, Traficantes de Sueños, Madrid.

Planas, Miriam (2017) “Chapter 10 A citizen wave to reclaim public and democratic water in Catalan municipalities" en Reclaiming Public Services: How cities and citizens are turning back privatisation, Published by Transnational Institute (TNI), [Coord.] Kishimoto, S y Petitjean, O. Multinationals Observatory, Austrian Federal Chamber of Labour (AK), European Federation of Public Service Unions (EPSU), Ingeniería Sin Fronteras Cataluña (ISF), Public Services International (PSI), Public Services International Research Unit (PSIRU), We Own It, Norwegian Union for Municipal and General Employees (Fagforbundet), Municipal Services Project (MSP) and Canadian Union of Public Employees (CUPE). Amsterdam and Paris ISBN 978-90-70563-58-5

Planas, Míriam I Martínez, Juan (2020): Chapter 10 A new water culture: Catalonia's public co-governance model in the making, The Future is Public: Towards Democratic Ownership of Public Services, Edited by Satoko Kishimoto, Lavinia Steinfort and Olivier Petitjean. Published by Transnational Institute (TNI), Multinationals Observatory, Austrian Federal Chamber of Labour (AK), Canadian Union of Public Employees (CUPE), Danish Union of Public Employees (FOA), De 99 Van Amsterdam, The Democracy Collaborative

B CLIVATGE, número 8

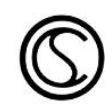


(US), European Federation of Public Service Unions (EPSU), Ingeniería Sin Fronteras Cataluña (ISF), MODATIMA (Movement of defence of water, land and the environment, Chile), Municipal Services Project (MSP), the Netherlands Trade Union Confederation (FNV), Norwegian Union for Municipal and General Employees (Fagforbundet), Public Services International (PSI), Public Services International Research Unit (PSIRU), University of Glasgow (Scotland) and We Own It (UK). tni.org/futureispublic.

Puello-Socarrás, José Francisco (2016); “De la gobernanza (neoliberal) a las gobernabilidades comunales Valorando las formas comunales de gobierno desde abajo como alternativas contra-hegemónicas" en Subversiones intelectuales Agosto de 2016 Bogotá, Colombia.

Radic, Juan (2016): “Crisis, indignación, alternativa política y refundación democrática. Bisagra del tiempo histórico en la España actual" en Sociología Histórica Revista de investigación acerca de la dimensión histórica de los fenómenos sociales Núm. 6/2016: 427-455, ISSN-e 22553851

Reglament de l'Observatori de l'Aigua de Terrassa

Rendueles, César y Joan Subirats (2016): Los Bienes Comunes ¿Oportunidad o ¿Espejismo? Barcelona: Icaria.

Roigé, Xavier, Beltran, Oriol y Estrada, Ferran (1993): “Diversidad Ecológica y propiedad comunal: El pueblo como organización política, económica y social en el Val D’Aran (Pirineos)" en Procesos de apropiación y gestión de recursos 
comunales [Coord] Pascual-Fernandez, Jose, Actas del VI Congreso de Antropología.

Simón, Inmaculada y Matés, José Manuel (2010): “El abastecimiento de agua potable en México y España, cambio institucional y aparición de las empresas (1870-1930)" en Agua, territorio y medio ambiente. Políticas públicas y participación ciudadana, [Coords.] Navarro, Jesús Raúl y Regalado, Jorge y Tortolero, Alejandro, Universidad de Guadalajara \& ATMA-CSIC, pp. 21-49, Guadalajara (México).

Varo, Anaïs, Puigdomnènech, Pol i Bagué, Edurne (2017): Les polítiques municipals d'aigua. Aproximació a la gestió collaborativa en l'àmbit municipal urbà de recursos essencials: el cas del servei d'aigua, Informe, en Salvador Martí i Puig (Coord.), Proyecto de Investigación Les Polítiques Municipals d'Aigua a Catalunya, Girona: Universidad de Girona.

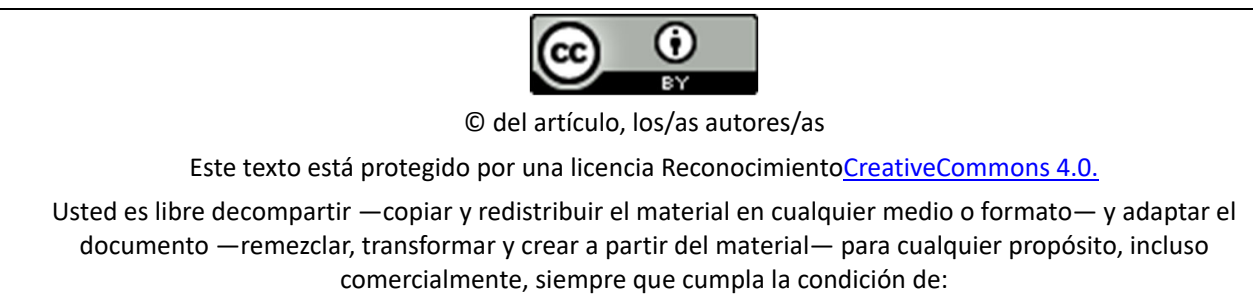

Atribución: Usted debe reconocer el crédito de una obra de manera adecuada, proporcionar un enlace a la licencia, e indicar si se han realizado cambios. Puede hacerlo en cualquier forma razonable, pero no de forma tal que sugiera que tiene el apoyo del licenciante o lo recibe por el uso que hace. 